\title{
The Efficacy of the Consumption of n-3 Polyunsaturated Fatty Acids for the Maintenance of Remission in Patients with Inflammatory Bowel Disease
}

\author{
Kan Uchiyama1*\#, Hiroko Aiki2\#, Aki Matsumura², Kanako Saruta², Ai Yuasa' ${ }^{2}$, Zensho Ito1, \\ Shinichiro Takami' ${ }^{1}$, Keisuke Saito ${ }^{1}$, Yuichiro Ohtaki ${ }^{1}$, Shizuka Suzuki ${ }^{1}$, Susumu Hayashi' \\ Shigeo Koido', Hiroshi Yoshida ${ }^{3}$, Toshifumi Ohkusa', Masayuki Saruta4 \\ ${ }^{1}$ Department of Internal Medicine, Division of Gastroenterology and Hepatology, The Jikei University Kashiwa Hospital, \\ Kashiwa, Japan \\ ${ }^{2}$ Department of Nutrition, The Jikei University Kashiwa Hospital, Kashiwa, Japan \\ ${ }^{3}$ Department of Laboratory Medicine, The Jikei University Kashiwa Hospital, Kashiwa, Japan \\ ${ }^{4}$ Department of Internal Medicine, Division of Gastroenterology and Hepatology, The Jikei University Hospital, \\ Tokyo, Japan \\ Email: *uchikan@jikei.ac.jp
}

How to cite this paper: Uchiyama, K., Aiki, H., Matsumura, A., Saruta, K., Yuasa, A., Ito, Z., Takami, S., Saito, K., Ohtaki, Y., Suzuki, S., Hayashi, S., Koido, S., Yoshida, H., Ohkusa, T. and Saruta, M. (2018) The Efficacy of the Consumption of n-3 Polyunsaturated Fatty Acids for the Maintenance of Remission in Patients with Inflammatory Bowel Disease. Food and Nutrition Sciences, 9, 105-118.

https://doi.org/10.4236/fns.2018.92009

Received: January 11, 2018

Accepted: February 21, 2018

Published: February 24, 2018

Copyright $(9) 2018$ by authors and Scientific Research Publishing Inc. This work is licensed under the Creative Commons Attribution International License (CC BY 4.0).

http://creativecommons.org/licenses/by/4.0/

\begin{abstract}
The aim of the present study was to investigate the efficacy of the actual consuming n-3 PUFA for remission-maintenance in IBD patients. A questionnaire on the dietary habits of patients one month before hospitalization (Q1) was completed by 24 patients with IBD (10 ulcerative colitis (UC) subjects and 14 Crohn's disease (CD) subjects) treated at our hospital. We educated the study subjects about an n-3 PUFA diet, and a follow-up survey (Q2) was conducted 6 to 12 months after discharge. Disease activity was evaluated using the International Organization for the Study of Inflammatory Bowel Disease (IOIBD) score and/or the Crohn's Disease Activity Index (CDAI) score for $\mathrm{CD}$ and the partial UCDAI score without endoscopic evaluation for UC. Q1 showed that the average n-3 and n-6 PUFA intakes were $1673 \pm 1651 \mathrm{mg}$ and $9146 \pm 5217 \mathrm{mg}$, respectively, and the average $\mathrm{n}-3 / \mathrm{n}-6$ ratio was $0.27 \pm 0.31$. In Q2, the intake of n-3 PUFA was significantly higher $(3671 \pm 1684 \mathrm{mg}, \mathrm{p}<$ 0.001 ), whereas the $\mathrm{n}-6$ PUFA intake decreased significantly (5217 $\pm 1973 \mathrm{mg}$, $\mathrm{p}<0.001)$ compared to those in Q1. As a consequence, the dietary $\mathrm{n}-3 / \mathrm{n}-6$ ratio was significantly increased $(0.87 \pm 0.60, p<0.001)$. Maintenance of the remission rate was significantly higher in IBD patients who complied with the $\mathrm{n}-3$ diet, and these patients maintained a dietary $\mathrm{n}-3 / \mathrm{n}-6$ ratio of 0.432 or higher ( 17 of 23 cases; $70.8 \%, \mathrm{p}<0.03$ ) compared to that observed for IBD
\end{abstract}


patients who did not comply with the diet. These results emphasize the importance of adjusting dietary PUFA and suggest that the n-3 diet may be effective in maintaining the remission of IBD.

\section{Keywords}

Crohn's Disease, Inflammatory Bowel Disease, N-3 Diet, Polyunsaturated Fatty Acid, Ulcerative Colitis

\section{Introduction}

In Japan, the intake of milk, animal meat, and vegetable oil began to increase from the 1960s onward, whereas the intake of fish products and cereals has decreased since the 1990s. As a result, the Western diet has become more mainstream among the current Japanese population, particularly young people [1] [2], despite traditional Japanese cuisine being added to the UNESCO List of Intangible Cultural Heritage in 2013. With this sudden change in dietary habits, the incidence of inflammatory bowel disease (IBD) [3] has rapidly increased in Japan. Consequently, the number of patients with IBD in Japan has been increasing since the 1980s, and an excess of 200,000 patients (ulcerative colitis, UC: approximately 160,000 patients; Crohn's disease, CD: approximately 40,000 patients) currently suffer from the condition. The role of excessive intake of fat in the Western diet is emphasized in IBD, particularly the excessive consumption of n-6 polyunsaturated fatty acids (PUFA), including linoleic acid (LA), an essential fatty acid contained in large amounts in vegetable oil. These n-6 PUFA increase the release of arachidonic acid (AA)-derived inflammatory mediators such as prostaglandin $\mathrm{E}_{2}\left(\mathrm{PGE}_{2}\right)$ and leukotriene $\mathrm{B}_{4}\left(\mathrm{LTB}_{4}\right)$, which exacerbate IBD.

With respect to n-3 PUFA, alpha-linolenic acid (ALA) is metabolized to eicosapentaenoic acid (EPA) and docosahexaenoic acid (DHA). N-3 PUFA are essential fatty acids present in large amounts in perilla oil and fish oils and inhibit the metabolism of n-6 PUFA by competitively antagonizing metabolic enzymes, such as delta 6- and delta 5-desaturases, cyclooxygenase (COX) and 5 lipoxygenase (LOX), thereby producing anti-inflammatory actions by inhibiting the synthesis of AA-derived inflammatory mediators and thromboxane $\mathrm{A}_{2}\left(\mathrm{TXA}_{2}\right)$. Therefore, it is thought that the regulation of the $n-3 / n-6$ ratio with a therapeutic diet may be important for reducing disease activity in patients with IBD. We previously reported that the $n-3 / n-6$ ratio of vital cell membrane phospholipids influenced the disease activities in IBD patients receiving dietary therapy that aimed to reduce the intake of n-6 PUFA and increase that of n-3 PUFA [4], i.e., the $\mathrm{n}-3$ diet. However, the influence of the actual intake of PUFA and the dietary $n-3 / n-6$ ratio on disease activity remains to be clarified. Therefore, we conducted a survey on the efficacy of and adherence to the $n-3$ diet. 


\section{Material and Methods}

\subsection{Subjects}

The participants were IBD patients who received treatment to induce remission at our hospital. Among the IBD patients who received hospitalization at the Jikei University Kashiwa Hospital between September 2010 and June 2012, 24 IBD patients who agreed with sufficient informed consent were taken as participants. The participants included $10 \mathrm{UC}$ patients and $14 \mathrm{CD}$ patients, and the mean age was $36.8 \pm 14.4$ years. Remission induction therapies are shown in Table 1.

\subsection{The n-3 Diet Using an "n-3 PUFA Food Exchange Table [4]"}

The $\mathrm{n}-3$ diet therapy regimen was developed at our hospital to control the dietary $n-3 / n-6$ ratio, which has been previously reported [4]. According to a national nutritional survey in Japan, the mean n- 6 and n-3 PUFA intakes were $10.5 \pm 5.5$ and $2.7 \pm 1.8 \mathrm{~g} /$ day, respectively, i.e., the n-6/n-3 ratio was approximately 4 [5]. In this regimen, to achieve an n-3/n- 6 ratio of approximately $1, n-6$ PUFA intake was restricted to $50 \%$ of the mean intake, and n-3 PUFA intake was increased 2 -fold compared with the mean. To target a daily n-6 PUFA intake of approximately $5.5 \mathrm{~g}$, the patients were prohibited from consuming the main sources of dietary n-6 PUFA, i.e., vegetable oil, seasonings such as margarine, certain salad dressings and mayonnaise, as well as fried foods and snacks. Furthermore, the target for n-3 PUFA ingestion was set at a total of $5100 \mathrm{mg}$ (3 units) per day. Approximately $3400 \mathrm{mg}$ ( 2 units) of ALA were ingested from approximately 7 $\mathrm{ml} /$ day of perilla oil in addition to a daily intake of approximately $1700 \mathrm{mg}$ (1 unit) from fish oil, i.e., EPA and DHA. The patients were able to confirm the n-3 PUFA contents of each fish using an "n-3 PUFA food exchange table" (Table 2).

\subsection{Questionnaire on Adherence to the Therapeutic Diet}

It is not possible conduct a detailed investigation of the intake of specific oils such as perilla oil from existing questionnaires, such as the self-administered diet history questionnaire, i.e., DHQ [6]. In the present study, we developed an

Table 1. Remission induction therapies.

\begin{tabular}{ccc}
\hline & UC & CD \\
\hline Gender (M, F) & M6, F4 & $\mathrm{n}=14$ \\
Age & $43.8 \pm 16.0$ & M11, F3 \\
5-ASA & 10 & $31.9 \pm 11.1$ \\
Corticosteroids & 5 & 13 \\
Calcineurin inhibitors & 4 & 1 \\
Infliximab/Adalimumab & 0 & 10 \\
Thiopurines & 6 & 3
\end{tabular}


Table 2. A partial extract from the "n-3 PUFA food exchange table" (1700 mg n-3 polyunsaturated fatty acids (n-3 PUFA) equals 1 unit).

\begin{tabular}{|c|c|c|}
\hline FOOD & Quantity & g/1 unit \\
\hline Chum salmon, raw & 1 slice, large & 210 \\
\hline Coho salmon, raw & $1 / 3$ slice, large & 70 \\
\hline Chum salmon, canned in brine & 1.5 cans, small & 130 \\
\hline Common Japanese conger eel, raw & 1 slice, small & 120 \\
\hline Horse mackerel, raw & 3, large & 210 \\
\hline Horse mackerel, salted and semi-dried, split & 1.5 , large & 110 \\
\hline Ayu sweet fish, cultured, raw & 6 , medium & 220 \\
\hline Anglerfish (liver) & 1 slice & 25 \\
\hline Three-line grunt, raw & 1 , small & 120 \\
\hline Sardines (Japanese pilchard), raw & 1.5 , medium & 60 \\
\hline Sardines (Japanese pilchard), salted and semi-dried: Maruboshi & 2, medium & 130 \\
\hline Sardines (Japanese pilchard), salted and dried: Mezashi & 2.5 , medium & 60 \\
\hline Sardines (Japanese pilchard), boiled and semidried whitebait & 6 cups & 410 \\
\hline Sardines (Japanese pilchard), boiled and canned with brining & $1 / 3$ can & 60 \\
\hline Japanese eel, Kabayaki & $1 / 2$ skewer, large & 60 \\
\hline Striped marlin, raw, red meat & 29 slices, large & 4500 \\
\hline Striped marlin, raw, fatty meat & 1.5 slices, large & 230 \\
\hline Skipjack, raw, caught in spring & 16 slices, large & 1500 \\
\hline Barracuda, raw & 1, large & 120 \\
\hline Amberjack, raw & 2 slice, medium & 160 \\
\hline Brown sole, raw & 5 slices, large & 720 \\
\hline Sablefish, raw & 1 slice, large & 160 \\
\hline Alfonsino, raw & 1 slice, large & 130 \\
\hline Mackerel, raw & 1.5 slices, medium & 110 \\
\hline Mackerel, salted and semi-dried: Hirakiboshi & $1 / 2$ slice, medium & 25 \\
\hline Mackerel, canned in brine & $1 / 2$ can & 60 \\
\hline Spanish mackerel, raw & 1 slice, large & 110 \\
\hline Pacific saury, raw & $1 / 2$, medium & 50 \\
\hline Pacific saury, salted and semi-dried: Hirakiboshi & $1 / 2$, medium & 50 \\
\hline Shishamo, raw & 6 , medium & 120 \\
\hline Japanese sea perch, raw & 2.5 slices, large & 200 \\
\hline Red sea bream, cultured, raw & 1 slice, medium & 90 \\
\hline Pacific cod, raw & 22 slices, large & 2500 \\
\hline Tarako, raw & 3.5 & 150 \\
\hline
\end{tabular}


original questionnaire to investigate the intake of n-3 PUFA and n-6 PUFA (Figure 1). The average value of representative products was adopted to

\begin{tabular}{|c|c|c|c|}
\hline & & & Date \\
\hline & & ID & \\
\hline & Dietary habits & survey of IBD & $C D \cdot U C$ \\
\hline $\begin{array}{l}\text { This survey contains } \\
\text { Please provide answe }\end{array}$ & $\begin{array}{l}\text { questions regarding } \\
\text { ers regarding your die }\end{array}$ & $\begin{array}{l}\text { your dietary habits. } \\
\text { et in the past month. }\end{array}$ & \\
\hline & & & \\
\hline & & & \\
\hline Please choose the most & st accurate answer. & & \\
\hline Number of meals & Number of light snacks & & \\
\hline ㄴ 4 or more times/day & ㅁ 4 or more times/day & & \\
\hline 口 3 times/day & 口 3 times/day & & \\
\hline ㅁ Twice/day & D Twice/day & & \\
\hline Once/day & 으o/day & & \\
\hline$\square$ Do noteat & $\square$ Do not eat & & \\
\hline Please provide answers & s for your in take frequen & cy in 1 month. & \\
\hline Perilla $\left(E_{g}\right.$ & Eg im a) oil & Chicken (in cluding & chicken products) \\
\hline Frequency & Intake & Frequency & Intake \\
\hline प More than once a day & More than $7 \mathrm{ml}$ & More than once a day & More than 2 servings \\
\hline 口 Once a day & ㅁ $2.6 \mathrm{ml}$ & 口 Once a day & ㅁ 1 serving \\
\hline ㅁ $4 \sim 6$ times/week & ㅁ $3.5 \mathrm{mI}$ & ㅁ $4 \sim 6$ times/week & ㅁ $1 / 2$ serving \\
\hline 므 $2 \sim 3$ times/week & ㅁ $1.8 \mathrm{ml}$ & 口 $2 \sim 3$ times/week & D Smallamount \\
\hline ㄴ. Less or once/week & $\square$ Less & Less or once/week & $\square$ Less \\
\hline Beef (including & beef products) & Pork (including & pork products) \\
\hline Frequency & Intake & Frequency & In take \\
\hline D More than once a day & More than 2 servings & More than once a day & More than 2 servings \\
\hline ㅁonce a day & $\square \quad 1$ serving & Once a day & ㅁ 1 serving \\
\hline ㅁ $4 \sim 6$ times/week & $\begin{array}{ll}\text { 미 } & 1 / 2 \text { serving }\end{array}$ & 口 $4 \sim 6$ times/week & $\begin{array}{l}\text { 마 } 1 / 2 \text { serving } \\
\end{array}$ \\
\hline 므 $2 \sim 3$ times/week & S Smallamount & 마 $2 \sim 3$ times/week & D Smallamount \\
\hline ㅁ Less or once/week & $\square \quad$ Less & $\square$ Less or once/week & $\square$ Less \\
\hline Fish (including large & amounts of fish oil) & Fish (including small & ( amounts of fish oil) \\
\hline Frequency & Intake & Frequency & In take \\
\hline ㅁ More than once a day & More than 2 servings & 口 More than once a day & 口 More than 2 servings \\
\hline D Once a day & 므 1 serving & Once a day & \begin{tabular}{|l|l|}
$\square$ & 1 serving \\
\end{tabular} \\
\hline ㅁ $4 \sim 6$ times/week & ㅁ $1 / 2$ serving & ㅁ $\quad 4 \sim 6$ times/week & 미 $1 / 2$ serving \\
\hline ㅁ $2 \sim 3$ times $/$ week & ㅁ $1 / 4$ serving & ㅁ $2 \sim 3$ times/week & ㅁ $1 / 4$ serving \\
\hline ㅁ Less or once/week & $\square \quad$ Less & ㅁ Less or once/week & $\square$ Less \\
\hline $\mathrm{Eg}$ & ggs & Milk and & d Yogurt \\
\hline Frequency & In take & Frequency & Intake \\
\hline ㅁ More than once a day & M More than three & D More than once a day & $\square$ More than 3 cups \\
\hline Oce a day & 口 Two & 口 Once a day & 2 cups \\
\hline 口 $\quad 4 \sim 6$ times/week & 口 One & 口 $4 \sim 6$ times/week & 口 1 cup \\
\hline 口 $2 \sim 3$ times/week & ㅁ Smallamount & ㅁ $2 \sim 3$ times/week & ㅁ $1 / 2$ cup \\
\hline$\square \quad$ Less or once/week & $\square \quad$ Less & $\square \quad$ Less or once/week & 口 Less \\
\hline Soypro & oducts & Mayonnaise a & and Dressings \\
\hline Frequency & Intake & Frequency & In take \\
\hline More than once a day & 2 paoks of natto and 1 pack of tofu & More than once a day & More than $30 \mathrm{~g}$ \\
\hline Once a day & D 1 saek of nato ond a $1 / 2$ peack of tortu & Once a day & 다 $15 \mathrm{~g}$ \\
\hline ㅁ $4 \sim 6$ times/week & 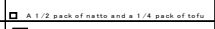 & ㅁ $\quad 4 \sim 6$ times/week & 口 $8 \mathrm{~g}$ \\
\hline 口 $2 \sim 3$ times $/$ week & ㅁ Smallamount & ㅁ $2 \sim 3$ times $/$ week & 口 $4 \mathrm{~g}$ \\
\hline$\square \quad$ Less or once/week & $\square \quad$ Less & $\square \quad$ Less or once/week & $\square$ Less than \\
\hline Fried food ( $U$ & Using olive oil) & Fried food (Not & using olive oil) \\
\hline Frequency & Intake & Frequency & Intake \\
\hline ㅁ More than once a day & More than 2 dishes & D More than once a day & $\square$ More than 2 dishes \\
\hline$\square$ Once a day & ㅁ 1 dish & Once a day & ㅁ 1 dish \\
\hline ㅁ $\quad 4 \sim 6$ times/week & a a $1 / 2$ dish & 口 $4 \sim 6$ times/week & a a $1 / 2$ dish \\
\hline 므 $2 \sim 3$ times/week & D Smallamount & 마 $2 \sim 3$ times/week & S Smallamount \\
\hline$\square$ Less or once/week & $\square \quad$ Less & $\square \quad$ Less or once/week & $\square \quad$ Less \\
\hline Fast $f$ & food & Ramen (In clud in & $g$ instant foods) \\
\hline Frequency & Intake & Frequency & Intake \\
\hline ㅁ More than once a day & Dore than 2 servings & 口 More than once a day & 口 More than 2 servings \\
\hline 口 Once a day & ㅁ 1 serving & 口 Once a day & 口 1 serving \\
\hline 口 $4 \sim 6$ times/week & ㅁ $1 / 2$ serving & ㅁ $4 \sim 6$ times/week & ㅁ $1 / 2$ serving \\
\hline 므 $2 \sim 3$ times/week & S Smallamount & 므 $2 \sim 3$ times/week & S Smallamount \\
\hline 므ss or once/week & I Less & L Less or once/week & I $\square$ Less \\
\hline Snacks such as & as potato chips & $\mathrm{Ca}$ & ke \\
\hline Frequency & Intake & Frequency & Intake \\
\hline D More than once a day & M More than $1 \mathrm{bag}$ & D More than once a day & D More than two pieces \\
\hline ㅁ Once a day & a $\mathrm{a} 1 / 2 \mathrm{bag}$ & Once a day & $\square \quad$ One piece \\
\hline ㅁ $\quad 4 \sim 6$ times $/$ week & a $1 / 4 \mathrm{bag}$ & ㅁ $4 \sim 6$ times/week & a a $1 / 2$ piece \\
\hline $\begin{array}{l}\square \sim 3 \text { times/week } \\
\end{array}$ & D Smallamount & $\begin{array}{ll}\square & 2 \sim 3 \text { times } / \text { week } \\
\end{array}$ & D Smallamount \\
\hline 므ss or once/week & $\square \quad$ Less & 口 Less or once/week & $\square \quad$ Less \\
\hline 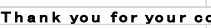 & & & \\
\hline
\end{tabular}

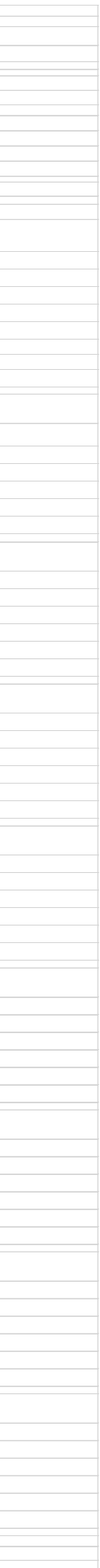

Figure 1. The questionnaire used to investigate the intake of n-3 and n-6 PUFA. An original questionnaire was developed to investigate the intake of PUFA in specific oils such as perilla oil. 
represent the fatty acid content in each food. We evaluated the approximate amount and intake frequency of those PUFA in each food, and we calculated the dietary n-3/n-6 ratio with these results.

A questionnaire regarding dietary habits one month prior to hospitalization (Q1) was completed by IBD patients treated at our hospital. We educated the study subjects on the n-3 diet, and a follow-up survey on the dietary habits (Q2) was conducted at 6 to 12 months after discharge (Figure 2).

\subsection{The Evaluation of Disease Activity}

Disease activity was evaluated using the International Organization for the study of Inflammatory Bowel Disease (IOIBD) score [7] and the Crohn's Disease Activity Index (CDAI) score [8] for CD or the partial UCDAI score [9] without endoscopic evaluation for UC. Using the UCDAI score, for UC, remission was defined as $0-1$ points, and relapse was defined as 2 or more points. For CD, remission was defined as $0-1$ points using the IOIBD score and less than 150 points using the CDAI score, whereas relapse was defined as 2 or more points using the IOIBD score or 150 points or higher using the CDAI score.

\subsection{Statistical Analysis}

For statistical analysis, we employed SPSS for Windows software (SPSS Japan, Tokyo, Japan). The changes in the dietary intake of PUFA were evaluated using a paired $t$-test. For comparisons between other non-paired independent groups, we employed the Student's $t$-test, Mann-Whitney U-test, or the chi-square test.

\section{Hospitalization \\ Inducing remission \\ Education of the $n-3$ diet \\ and \\ Q1; a questionnaire about the dietary habits of one month before hospitalization}

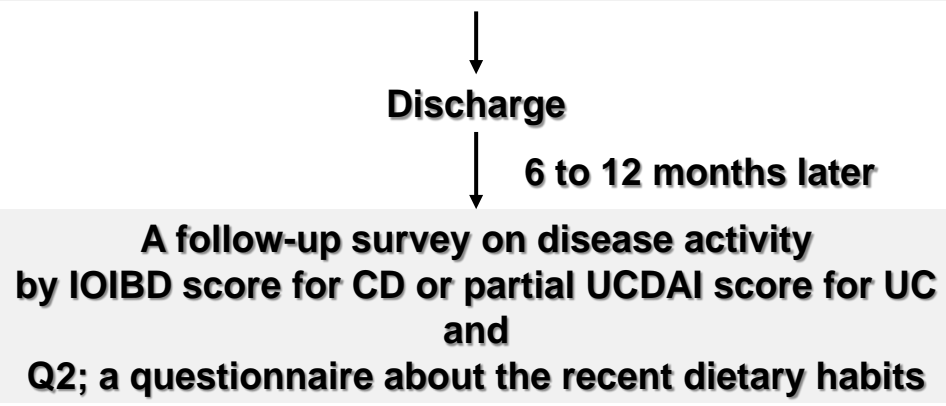

Figure 2. Study flowchart. A questionnaire regarding dietary habits one month prior to hospitalization (Q1) was completed by IBD patients treated at our hospital, and we educated the study subjects on the n-3 diet. At 6 to 12 months after discharge, a follow-up survey on the dietary habits (Q2) was conducted, and disease activity was evaluated using the IOIBD score and CDAI for CD or partial UCDAI score without endoscopic evaluation for UC. 
Cumulative remission maintenance rate was evaluated using a log-rank test. All p-values less than 0.05 were considered significant.

\subsection{Ethics}

These experiments were approved by the Ethics Committee of the Jikei University School of Medicine (No. 6309).

\section{Results}

\subsection{Results of Questionnaire}

At Q1, the average intakes of n-3 PUFA and n-6 PUFA were $1673 \pm 1,651 \mathrm{mg}$ (95\% CI: 975.4 to 2370.0 ) and $9146 \pm 5217 \mathrm{mg}$ (95\% CI: 7293.7 to 10998.0), respectively, and the average n-3/n-6 ratio was $0.27 \pm 0.31$ (95\% CI: 0.14 to 0.40 ). The intake of n-3 PUFA in Q2 increased significantly (3671 $\pm 1684 \mathrm{mg}, 95 \% \mathrm{CI}$ : 2959.8 to $4382.3, \mathrm{p}<0.001$ ) over that in Q1, whereas the $\mathrm{n}-6$ PUFA intake in Q2 decreased significantly $(5217 \pm 1973 \mathrm{mg}, 95 \% \mathrm{CI}: 4383.5$ to $6049.7, \mathrm{p}<0.001)$ compared with Q1 (Figure 3). Consequently, the dietary n-3/n-6 ratio was significantly increased $(0.87 \pm 0.60,95 \% \mathrm{CI}: 0.61$ to $1.12, \mathrm{p}<0.001)$ after receiving education about the n-3 diet (Figure 4).

\subsection{Disease Activity and Dietary Fatty Acids}

Regarding disease activity, 16 of 24 cases (66.7\%) maintained remission at Q2, and the average n-3 PUFA intake and n-3/n-6 ratio tended to be lower in relapsed patients compared to patients in remission $(2,787.7 \pm 1,883.8 \mathrm{mg}$ vs. $4112.7 \pm 1438.7 \mathrm{mg} ; \mathrm{p}=0.068,0.65 \pm 0.56$ vs. $0.98 \pm 0.60 ; \mathrm{p}=0.22$, respectively), whereas there was no difference in the intake of n-6 PUFA in both groups (5387 $\pm 2070 \mathrm{mg}$ vs. $5131 \pm 1986 \mathrm{mg} ; \mathrm{p}=0.77$ ) (Figure 5 and Figure 6).

\section{Changes in the intake of PUFAs}
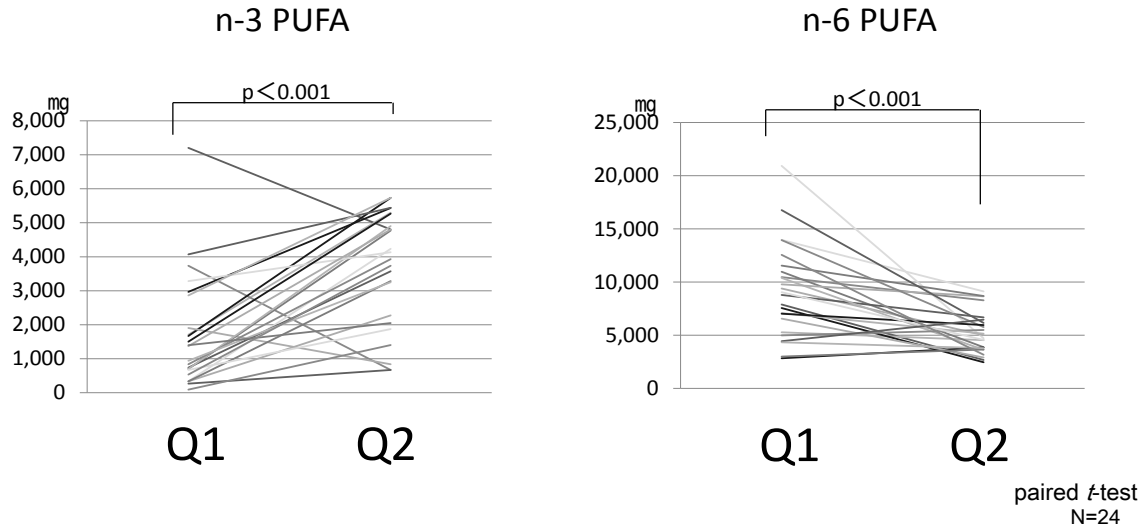

Figure 3. Changes in the intake of PUFAs. The intake of n-3 PUFA in Q2 was increased significantly (3671 $\pm 1684 \mathrm{mg}$, 95\% CI: 2959.8 to 4382.3 , p < 0.001) over that in Q1, whereas n-6 PUFA intake in Q2 was decreased significantly (5217 \pm 1973 mg, 95\% CI: 4383.5 to 6049.7, $\mathrm{p}<0.001$ ) versus that in $\mathrm{Q} 1$. 


\section{Changes in the ratio of $n-3 / n-6$}

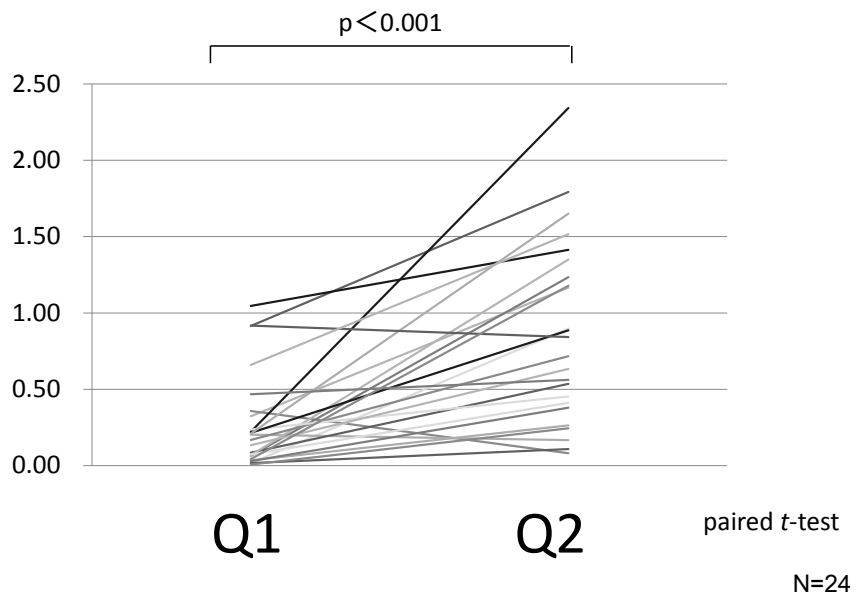

Figure 4. Changes in the ratio of n-3/n-6. The dietary $n-3 / n-6$ ratio was significantly increased $(0.87 \pm 0.60,95 \% \mathrm{CI}: 0.61$ to $1.12, \mathrm{p}<0.001)$ as a result of the $\mathrm{n}-3$ dietary education.

Comparison of the $n-3 / n-6$ ratio between remission maintenance patients and relapse patients

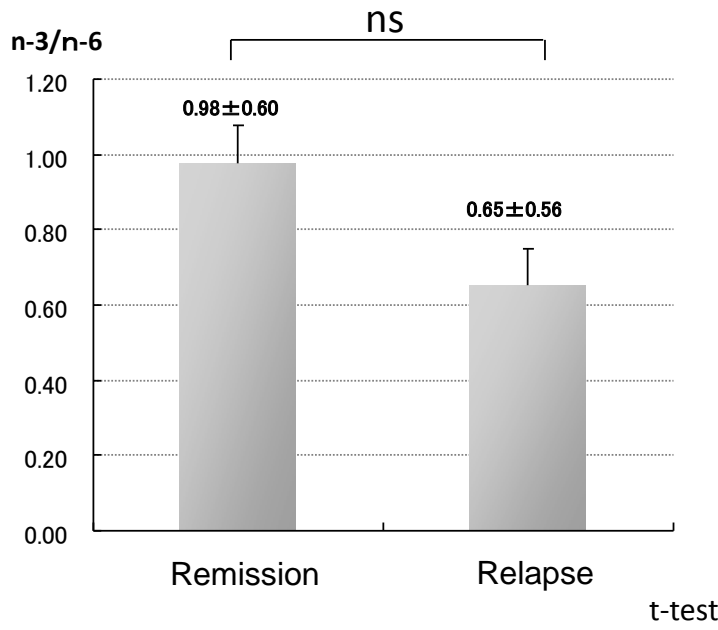

$\mathrm{N}=24$

Figure 5. Comparison of the n-3/n-6 ratio between patients with remission maintenance and those with relapse. At Q2, the n-3/n-6 ratio tended to be lower in relapsed patients than that in patients in remission $(0.65 \pm 0.56$ vs. $0.98 \pm 0.60 ; \mathrm{p}=0.22$, respectively).

\subsection{Optimal Dietary n-3/n-6 Ratio for Remission Maintenance of IBD}

Receiver operating characteristic (ROC) curve analysis was performed to assess the intake of $\mathrm{n}$-3 PUFA for the prediction of remission maintenance in Q2. As a result, at $3832.8 \mathrm{mg}$ of n-3 PUFA, the area under the ROC curve (AUC) was 0.719 , and the sensitivity and specificity were $68.8 \%$ and $75.0 \%$, respectively. Thirteen of the 24 participants (54.2\%) adhered to the intake of n-3 PUFA, i.e., 


\section{Comparisons of the intake of n-3 PUFA and n-6 PUFA}
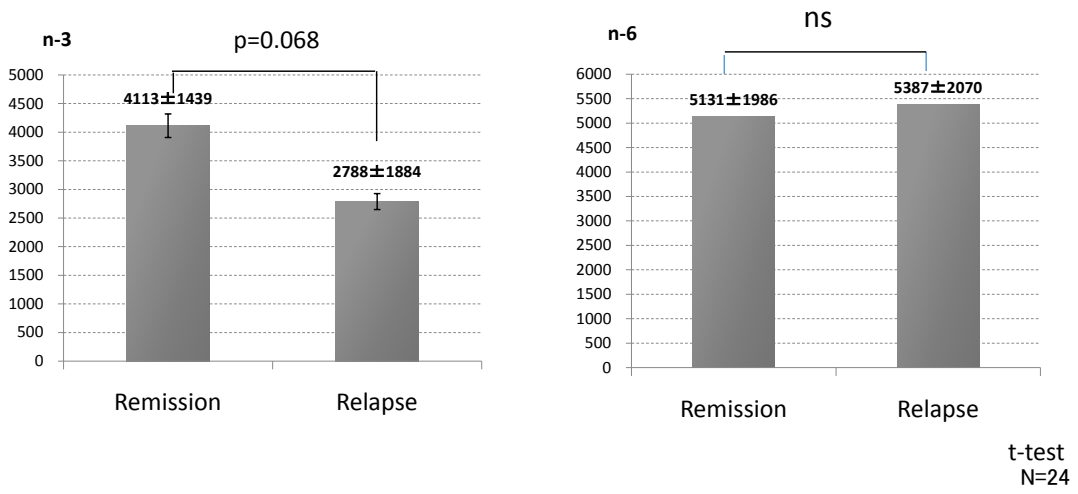

Figure 6. Comparison of the intake of n-3 PUFA and n-6 PUFA. At Q2, the average n-3 PUFA intake tended to be lower in relapsed patients than that in patients in remission $(2787.7 \pm 1883.8 \mathrm{mg}$ vs. $4112.7 \pm 1438.7 \mathrm{mg} ; \mathrm{p}=0.068$, respectively $)$, whereas that of $\mathrm{n}-6$ PUFA did not differ between groups $(5387 \pm 2070 \mathrm{mg}$ vs. $5131 \pm 1986 \mathrm{mg} ; \mathrm{p}=0.77)$.

$3833 \mathrm{mg}$ or higher per day, and 11 of these 13 cases $(84.6 \%)$ were able to maintain remission, whereas only 5 of the other 11 participants (45.5\%) with $n-3$ PUFA intake less than $3833 \mathrm{mg}$ were able to maintain remission, although this difference was not statistically significant $(p=0.055)$. Similarly, ROC curve analysis was performed to assess the dietary n-3/n-6 ratio for the prediction of remission maintenance in Q2. The AUC was 0.680 , and the sensitivity and specificity were $87.5 \%$ and $62.5 \%$, respectively, at an $n-3 / n-6$ ratio of 0.432 . The remission maintenance rate was significantly higher in IBD patients who complied with the n-3 diet and maintained a dietary n-3/n-6 ratio of 0.432 or higher ( 17 of 23 cases; 70.8\%, p < 0.03) (Figure 7) compared to those who were not in compliance. The cumulative relapse-free survival was higher in patients who maintained n-3/n-6 ratio of 0.432 or higher (Log-rank test, $\mathrm{p}=0.011$ ) (Figure 8).

\section{Discussion}

In Japan, the consumption of a Western diet is considered an etiological environmental factor related to the recent increase in the incidence of IBD [3]. In particular, the role of excessive fat intake has been emphasized in this disease. In the EPIC study of IBD, Tjonneland et al. [10] reported that a large intake of LA and n-6 PUFA was associated with an increased risk of UC. Excessive consumption of the n-6 PUFA contained in vegetable oils may increase the release of inflammatory mediators such as PGE2 and LTB4, which can exacerbate various allergic diseases as well as IBD. In our previous report, we showed that the activity of delta 6 desaturase, which metabolizes LA to gamma linolenic acid, was significantly higher in $C D$ patients than that in healthy subjects. In addition, the percentage weight of AA in vital cell membranes was significantly higher in patients with CD than in healthy subjects and in patients with UC [11]. Therefore, LA may be efficiently metabolized to AA in patients with $\mathrm{CD}$. Other previous 


\section{The n-3 / n-6 ratio and remission maintenance rate}

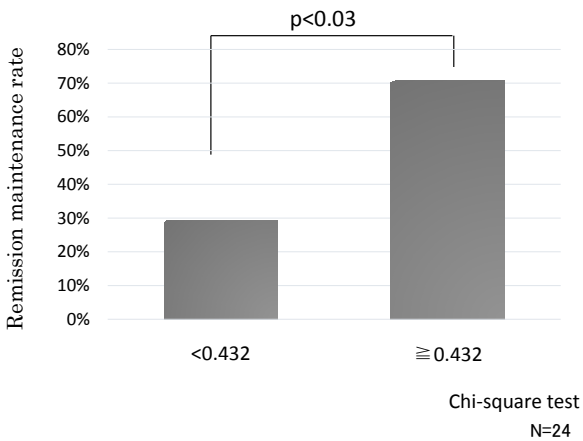

Figure 7. The n-3/n-6 ratio and remission maintenance rate. The remission maintenance rate was significantly higher in IBD patients who complied with the $n-3$ diet and maintained a dietary n-3/n- 6 ratio of 0.432 or higher ( 17 of 23 cases; $70.8 \%, p<0.03$ ) compared to those who were not in compliance.

\section{Kaplan-Meier curves for patients remaining in clinical remission.}

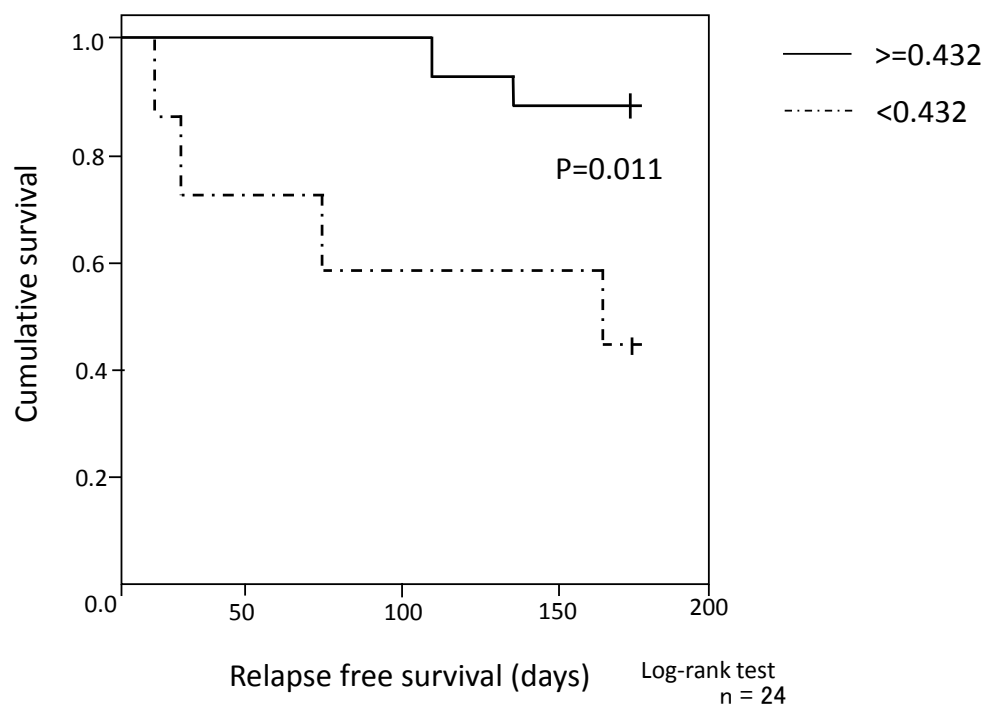

Figure 8. Kaplan-Meier curves for patients remaining in clinical remission. The cumulative relapse-free survival was significantly higher in patients who maintained n-3/n-6 ratio of 0.432 or higher (Log-rank test, $\mathrm{p}=0.011$ ).

studies have confirmed an increase in LTB4 production in the intestinal mucosa of patients with UC and CD [12]. On the other hand, n-3 PUFA may inhibit the production of inflammatory mediators by antagonizing the metabolism of LA, thereby causing immunosuppressive effects [13] [14] [15]. Therefore, it is desirable to reduce the percentage weights of AA in vital cell membranes to control the disease activity of IBD through the proactive consumption of $n-3$ PUFA. Belluzzi et al. [16] reported that fish oil incorporated into phospholipids and reduced the percentage weights of AA both in plasma and in the membranes of 
red blood cells. Furthermore, Lands et al. [17] reported that the restricted intake of LA and a high consumption of n-3 PUFA efficiently decreased the percentage weights of AA and DGLA in phospholipids. Thus, as dietary therapy, both intake restriction of n-6 PUFA and proactive ingestion of n-3 PUFA may be desirable to reduce the disease activity of IBD. In our previous report, we showed that dietary fatty acid content reflected the fatty acid composition of the cellular membranes and that the n-3 diet significantly increased the n-3/n-6 ratio of the cell membranes of erythrocytes and was effective at maintaining IBD remission [4]. Similarly, another previous report revealed that a novel enteric-coated fish oil preparation was effective at reducing the rate of relapse in patients with CD in remission [18]. Currently, Scaioli E [19], et al. reported that highly purified EPA capsules reduced fecal calprotectin levels and prevents clinical relapse in UC patients. Thus, these previous reports suggest that dietary fatty acid intake is strongly linked with the disease activity characteristics of IBD and that adjustment of dietary PUFA is important. However, whether IBD patients could adhere to the n-3 diet regimen remained unclear, and the relationship between the actual PUFA intake and the remission maintenance rate of IBD was not reported. Therefore, in the present study, we conducted a questionnaire on patient adherence to the n-3 diet therapy using an original questionnaire and evaluated the efficacy of the therapeutic diet for the maintenance of remission in IBD patients.

We found that the mean intakes of n-6 PUFA and n-3 PUFA were $9146 \pm$ 5217 and $1673 \pm 1651 \mathrm{mg} /$ day before hospitalization, respectively. Compared with the results of the national survey mentioned above, the mean intake of $n-3$ PUFA before hospitalization was significantly lower (one-sample $t$-test; $\mathrm{p}<$ 0.01 ), while there was no significant difference for that of n-6 PUFA (one sample $t$-test; $\mathrm{p}=0.144$ ). After education, the mean intakes of $\mathrm{n}-6$ and $\mathrm{n}-3$ PUFA were $5.22 \pm 1.97$ and $3.67 \pm 1.68 \mathrm{~g} /$ day, respectively. In the $\mathrm{n}-3$ diet regimen, the intake of n-6 PUFA was restricted to $50 \%$ of the mean intake, i.e., approximately $5.5 \mathrm{~g} /$ day, and n-3 PUFA intake was increased approximately 2 -fold compared to the mean intake found in the national survey, i.e., $5.1 \mathrm{~g}$ (3 units) a day. According to these results, adherence to the intake restriction of n-6 PUFA was sufficient. Although the intake of n-3 PUFA after education was increased significantly over the level before hospitalization $(\mathrm{p}<0.001)$, it did not reach the target intake level. The average n-3 PUFA intake at Q2 tended to be lower in relapsed patients than that in patients in remission $(\mathrm{p}=0.068)$. It is thought that low adherence to n-3 PUFA intake affect relapse. However, the dietary n-3/n-6 ratio was significantly increased, and 17 of 24 participants $(70.8 \%)$ achieved the 0.432 ratio, derived by ROC curve analysis. Additionally, 14 of 17 patients (82.4\%) who maintained a dietary n-3/n-6 ratio of 0.432 or higher maintained remission $(\mathrm{p}<0.03)$. Interestingly, a positive correlation was found between the intake of n-6 PUFA before hospitalization (Q1) and the UCDAI score in Q2 in UC patients $\left(\mathrm{y}=0.0006 \mathrm{x}-3.7309, \mathrm{R}^{2}=0.485, \mathrm{p}<0.01, \rho=0.798\right)$. Therefore, UC pa- 
tients with high n-6 PUFA intake before remission may relapse easily. This result suggests that IBD patients, especially UC patients, should refrain from the ingestion of n-6 PUFA on a long-term basis. Although the intake of fat has increased with the spread of the Western style diet in Japan, the absolute intake of n-6 PUFA in the Japanese population may be less compared with that of Westerners, and for Japanese IBD patients, the acceptance of traditional Japanese cuisine such as marine products, including those foods rich in n-3 PUFA, may be higher compared to those in the diets of Westerners. In this study, all subject-patients were from a single nation, i.e., Japan. Therefore, the possibility that these effects of the n-3 diet and these results are limited to Japanese subjects cannot be excluded. Moreover, in this study, adherence to medications was not investigated, and a correlation between adherence to the therapeutic diet and adherence to medication regimens cannot be excluded and may have affected our results. Moreover, the number of patients in this study was small, so we must consider the possibility that these factors affected the results of this study. The results will be more convinced if the sample size is larger. In the future, we intend to enroll a larger number of IBD patients for further assessment with multiple regression analysis for the related factors.

\section{Conclusion}

These results suggest that adherence to the $\mathrm{n}-3$ diet and its impact on the maintenance of remission may be achieved by understanding the importance of adjustments to dietary PUFA.

\section{Conflicts of Interest}

The authors declare no conflicts of interest.

\section{References}

[1] Adachi, H. and Hino, A. (2005) Trends in Nutritional Intake and Serum Cholesterol Levels over 40 Years in Tanushimaru, Japanese Men. Journal of Epidemiology, 15, 85-89. https://doi.org/10.2188/jea.15.85

[2] Igarashi, O., Sugano, M. and Ikeda, I. (1998) A Modern Viewpoint of the Fatty Acid nutrition. Japanese Society of Nutrition and Food Science (in Japanese). Koseikan, Tokyo.

[3] Asakura, K., Nishiwaki, Y., Inoue, N., Hibi, T., Watanabe, M. and Takebayashi, T. (2009) Prevalence of Ulcerative Colitis and Crohn's Disease in Japan. Journal of Gastroenterology, 44, 659-665. https://doi.org/10.1007/s00535-009-0057-3

[4] Uchiyama, K., Nakamura, M., Odahara, S., Koido, S., Katahira, K., Shiraishi, H., Ohkusa, T., Fujise, K. and Tajiri, H. (2010) n-3 Polyunsaturated Fatty Acid Diet Therapy for Patients with Inflammatory Bowel Disease. Inflammatory Bowel Diseases, 16, 1696-1707. https://doi.org/10.1002/ibd.21251

[5] (2005) Diet Intake Standards in Japanese Established by the Ministry of Health, Labour and Welfare (2005 Version). Daiichi Shuppan, Tokyo.

[6] Sasaki, S., Yanagibori, R. and Amano, K. (1998) Self-Administered Diet History 
Questionnaire Developed for Health Education: A Relative Validation of the Test-Version by Comparison with 3-Day Diet Record in Women. Journal of Epidemiology, 8, 203-215. https://doi.org/10.2188/jea.8.203

[7] Myren, J., Bouchier, I.A., Watkinson, G., Softley, A., Clamp, S.E. and de Dombal, F.T. (1984) The OMGE Multinational Inflammatory Bowel Disease Survey 1976-1982. A Further Report on 2657 Cases. Scandinavian Journal of Gastroenterology, 19, 1-27.

[8] Best, W.R., Becktel, J.M., Singleton, J.W. and Kern, F. (1976) Development of a Crohn's Disease Activity Index. National Cooperative Crohn's Disease Study. Gastroenterology, 70, 439-444.

[9] Sutherland, L.R., Martin, F., Greer, S., Robinson, M., Greenberger, N., Saibil, F., Martin, T., Sparr, J., Prokipchuk, E. and Borgen, L. (1987) 5-Aminosalicylic Acid Enema in the Treatment of Distal Ulcerative Colitis, Proctosigmoiditis, and Proctitis. Gastroenterology, 92, 1894-1898. https://doi.org/10.1016/0016-5085(87)90621-4

[10] Tjonneland, A., Overvad, K., Bergmann, M.M., Nagel, G., Linseisen, J., Hallmans, G., Palmqvist, R., Sjodin, H., Hagglund, G., Berglund, G., Lindgren, S., Grip, O., Palli, D., Day, N.E., Khaw, K.T., Bingham, S., Riboli, E., Kennedy, H. and Hart, A., The IBD in EPIC Study Investigators. (2009) Linoleic Acid, a Dietary n-6 Polyunsaturated Fatty Acid, and the Aetiology of Ulcerative Colitis: A Nested Case-Control Study within a European Prospective Cohort Study. Gut, 58, 1606-1611. https://doi.org/10.1136/gut.2008.169078

[11] Uchiyama, K., Odahara, S., Nakamura, M., Koido, S., Katahira, K., Shiraishi, H., Ohkusa, T., Fujise, K. and Tajiri, H. (2013) The Fatty Acid Profile of the Erythrocyte Membrane in Initial-Onset Inflammatory Bowel Disease Patients. Digestive Diseas es and Sciences, 58, 1235-1243. https://doi.org/10.1007/s10620-012-2508-6

[12] Sharon, P. and Stenson, W.F. (1984) Enhanced Synthesis of Leukotriene B4 by Colonic Mucosa in Inflammatory Bowel Disease. Gastroenterology, 86, 453-460.

[13] Shimizu, T., Fujii, T., Suzuki, R., Igarashi, J., Ohtsuka, Y., Nagata, S. and Yamashiro, Y. (2003) Effects of Highly Purified Eicosapentaenoic Acid on Erythrocyte Fatty Acid Composition and Leukocyte and Colonic Mucosa Leukotriene B4 Production in Children with Ulcerative Colitis. Journal of Pediatric Gastroenterology and $\mathrm{Nu}$ trition, 37, 581-585. https://doi.org/10.1097/00005176-200311000-00015

[14] Almallah, Y.Z., El-Tahir, A., Heys, S.D., Richardson, S. and Eremin, O. (2000) Distal Procto-Colitis and n-3 Polyunsaturated Fatty Acids: The Mechanism(s) of Natural Cytotoxicity Inhibition. European Journal of Clinical Investigation, 30, 58-65. https://doi.org/10.1046/j.1365-2362.2000.00581.x

[15] Almallah, Y.Z., Ewen, S.W., El-Tahir, A., Mowat, N.A., Brunt, P.W., Sinclair, T.S., Heys, S.D. and Eremin, O. (2000) Distal Proctocolitis and n-3 Polyunsaturated Fatty Acids (n-3 PUFAs): The Mucosal Effect in Situ. Journal of Clinical Immunology, 20, 68-76. https://doi.org/10.1023/A:1006698728816

[16] Belluzzi, A., Brignola, C., Campieri, M., Camporesi, E.P., Gionchetti, P., Rizzello, F., Belloli, C., De Simone, G., Boschi, S., Miglioli, M. and Barbara, L. (1994) Effects of New Fish Oil Derivative on Fatty Acid Phospholipid-Membrane Pattern in a Group of Crohn's Disease Patients. Digestive Diseases and Sciences, 39, 2589-2594. https://doi.org/10.1007/BF02087694

[17] Lands, W.E., Libelt, B., Morris, A., Kramer, N.C., Prewitt, T.E., Bowen, P., Schmeisser, D., Davidson, M.H. and Burns, J.H. (1992) Maintenance of Lower Proportions of (n-6) Eicosanoid Precursors in Phospholipids of Human Plasma in Response to Added Dietary (n-3) Fatty Acids. Biochimica et Biophysica Acta, 1180, 
147-162. https://doi.org/10.1016/0925-4439(92)90063-S

[18] Belluzzi, A., Brignola, C., Campieri, M., Pera, A., Boschi, S. and Miglioli, M. (1996) Effect of an Enteric-Coated Fish-Oil Preparation on Relapses in Crohn's Disease. The New England Journal of Medicine, 334, 1557-1560.

https://doi.org/10.1056/NEJM199606133342401

[19] Scaioli, E., Sartini, A., Bellanova, M., Campieri, M., Festi, D., Bazzoli, F. and Belluzzi, A. (2017) Highly Purified Eicosapentaenoic Acid, as Free Fatty Acid, Reduces Fecal Calprotectin Levels and Prevents Clinical Relapse in Ulcerative Colitis Patients: A Double-Blind, Randomized, Placebo Controlled Trial. Journal of Crohn's and Colitis, 11, S376. 